\title{
COPS, DRUGS AND THE COMMUNITY: ESTABLISHING CONSULTATIVE HARM REDUCTION STRUCTURES IN TWO WESTERN AUSTRALIAN LOCATIONS
}

Richard Midford, Senior Research Fellow

John Acres, Research Associate

Simon Lenton, Research Fellow

Wendy Loxley, Associate Professor

Kevin Boots, Research Fellow

National Drug Research Institute

Curtin University of Technology, Perth WA.

Published as: Midford, R., Acres, J., Lenton, S., Loxley, W., Boots, K. (2002) Cops, drugs and the community: establishing consultative harm reduction structures in two West Australian locations. International Journal of Drug Policy. 13(3), 181-188.

Please address all correspondence to:

Richard Midford

Senior Research Fellow

National Drug Research Institute

Curtin University

GPO Box U1987

Perth, WA 6845

richard@ndri.curtin.edu.au 


\begin{abstract}
In Australia a police project incorporating four parallel trials was established to test a new model of illicit drug law enforcement, which gives greater emphasis to harm reduction at the community level. The project was based on a community-policing model developed in the United Kingdom and involved establishing a community based consultation structure comprising an implementation oriented Drug Action Team (DAT) and support oriented Drug Reference Group (DRG). Two of the trials operated in Western Australia: one in Geraldton, a small regional city; and the other in Mirrabooka, a large, diverse, metropolitan region within Perth. The project officers were faced with a number of challenges and had to develop strategies to overcome these. One of the important issues was the effect of continual changes in membership of DATs, and consequent fluctuating levels of enthusiasm and commitment. The size and composition of the DATs also had an impact on how they operated. Other issues included the management of different agency agendas and recognition that the project would only operate for a limited time. How the project officers dealt with these issues in their development of the DAT/DRG model and how the two trial sites incorporated harm reduction into illicit drug policing are presented and discussed.
\end{abstract}




\section{Introduction}

Within the Australian law enforcement community there has been a growing recognition that traditional policing responses to drug trafficking and use have not reduced supply or demand. Despite conscientious efforts, significant and prolonged effects on the street level availability, price or purity of illicit drugs have not been achieved (Parliamentary Joint Committee on the National Crime Authority, 1989). There are now more users, using more drugs than ever before (Hall, 1995) and a huge amount of police resources remain focused on deterring use, despite the evidence that such an approach has not achieved its intended outcomes. Indeed, the affluent, liberal, democratic nature of Australian society and the trend towards viewing drug use as a health rather than a law enforcement problem means that punitive, legal responses are never going to solve the 'drug problem'. The social factors that generate drug use are simply too complex to be dealt with solely by deterrence.

In addition to acknowledging the complex aetiology of drug use, there needs to be recognition of the wide range of harms associated with problematic drug. Individual users, family and friends, the wider community and health, justice and welfare service agencies are all affected. Harm reduction efforts were initially focused on the individual user and emphasised users surviving their drug experience with minimal long-term health, social or economic consequences. However, more recently, there has been an increased focus on the level of community harm caused by activities associated with the acquisition and use of illicit drugs. Examples of such harm include unsafe needle disposal practices, the spread of blood born viruses through needle sharing, and property crime associated with funding the purchase of drugs.

There is also a growing recognition that with an increased emphasis on community policing approaches, the police have an integral role in reducing the harms of drug use. However, they are only part of the equation. A system perspective identifies that drug using behaviour is influenced by a multitude of factors, both individual and contextual (Holder, 1992). Police are players within a broader system, along with drug users, their families, health and welfare agencies, and the community. The police operating in isolation, within their traditional roles are capable of achieving only so much. Similarly other stake holders are limited in what they can achieve if they do not 
deal with drug use in a way that takes into consideration the interaction of the individual drug user with their social, economic, and physical environmental (Gruenewald, Treno, Taff and Klitzner, 1997; Holder, 1992). A logical deduction from a systems view of drug use is that greater efficiencies may flow from collaboration between the various players that comprise the system. The police for their part have begun a long process of examination, modification and adaptation of their views and actions in drug law enforcement. Sutton and James (1996) in a reexamination of illicit drug policing goals outlined many areas where change would be beneficial. These authors pointed to the benefits that would likely flow from remodelling drug law enforcement so as to deal pragmatically with the day to day harms, rather than pursuing the 'Mr Bigs' of the drug trade, who have proved very difficult to successfully prosecute.

In July 1996, the Ministerial Council on Drug Strategy (MCDS) agreed to the development and evaluation of a national community based approach to drug law enforcement that was consistent with the National Drug Strategy (National Drug Strategy Committee, 1993) and drew on the recommendations of Sutton and James' (1996) report, 'Evaluation of Australian Drug Anti-trafficking Law Enforcement'. A Board of Control was established to manage the National Community Based Approach to Drug Law Enforcement (NCBADLE), which became an entity designed co-ordinate and resource a range of programs aimed at reorienting illicit drug law enforcement so as to reduce drug related harm in the community.

The terms of reference for NCBADLE's Board of Control (undated) specifically stated that these programs should address the five key issues identified by Sutton and James (1996), namely:

1. develop a framework to integrate drug policing and give a greater focus to harm reduction

2. ensure more effective assessment of outcomes, including development of common data collection systems

3. enhance cross sectoral collaboration as a way of achieving an integrated approach to demand reduction and harm reduction 
4. develop a shared understanding of harm reduction across stakeholding agencies

5. develop an integrated training strategy for police and other stakeholding agencies

These are long term objectives, with no one initiative intended to supply the whole solution. Rather, multiple initiatives were intended to bring about progressive change in the police's role and culture. One such initiative selected by the NCBADLE Board of Control involved a trial of a community collaboration based on a model developed in the United Kingdom (Lord President of the Council et al, 1995; Duke and MacGregor, 1997). Briefly, in the UK model, local statutory authorities such as police, social services, health and education meet to identify and discuss local patterns of illicit drug use and the associated problems for both drug users and the community. These groups are known as Drug Action Teams or DATs (Lord President of the Council et al, 1995; Duke and MacGregor, 1997). Having identified the local pattern of problems, these groups would then look at what could realistically be achieved at an operational level to deal with these problems. They would then implement a range of local programs specifically designed to reduce the identified problems.

A vital aspect of the UK model is that the DATs are part of a "Whole of Government" approach, and provide a mechanism for a diverse range of government organisations to co-ordinate their responses to drug-related problems (Lord President of the Council et al, 1995). The DATs are advised by Drug Reference Groups (DRGs) comprising community members and a range of interested parties with local knowledge about drug use and harm. The role of the DRG is to provide local support for the operation of the DAT.

This model, with some modification, has been piloted in four sites across Australia; Mirrabooka and Geraldton in Western Australia, Fairfield in NSW and Morwell in Victoria. These sites were selected to reflect a broad cross section of Australia's population and as communities experiencing a range of evident drug related harm. In order to investigate how these four trials attempted to meet the objectives of the NCBADLE Board and to determine the most effective processes, the National Drug Research Institute and the Criminology Department of the University of Melbourne 
were contracted to evaluate the project as a whole. This paper outlines some of the initial findings of this evaluation, drawn from the two Western Australian sites.

\section{Evaluation of Implementation}

In WA the NCBADLE DAT/DRG model varied somewhat from the UK original. There was also substantial variation between WA and the two other jurisdictions, because of differences in existing bureaucratic structures and the different problems faced in each location. Accordingly this paper looks at how the original model was modified to suit implementation circumstances in WA. In comparison with UK practice, the two trials in WA gave greater emphasis to immediately beneficial harm reduction activities and less effort was devoted to gathering local drug use statistics, because of the finite nature of the project. However, there was also an important structural difference in the relationship between the DAT and the DRG. The model was adapted to use the existing crime oriented, Safer WA committees in the role of the DRG. These local committees are coordinated by the police and bring together key community, police and heath agency personnel in order share understanding on ways to reduce the level of crime and the consequences of crime in their regions. They were not established specifically to focus on drug use and harm and consequently are not best placed to provide local drug intelligence, although they do provide good links to the community.

Whilst recognising that the local Safer WA committee may not be an ideal support group for the DAT, this adaptation was considered the best option in Western Australia, as each local committee was an established group, with strong links to the community and service agencies. It was felt that the membership of any DRG, established specifically for this project, would consist entirely of those agencies and individuals already sitting on the Safer WA committee. It was also considered unlikely that an additional committee with overlapping objectives would receive sufficient support from the agencies or the community. Indeed, there was a concern that an additional and independent DRG could prove detrimental to the overall functioning of the Safer WA committees. 
The DAT component of the UK model was translated more accurately in terms of structure and operation. In Western Australia each of the DATs comprised senior personnel from local mainly health-related agencies and was coordinated by its own dedicated project officer. These were employed by the police as unsworn officers. The project officer's role was to initially establish the DAT, then act as a resource to the DAT and as a point of liaison between the health agencies and the police.

\section{Evaluation Methodology}

Implementation of the project at the two Western Australian sites was evaluated using a variety of approaches, selected on the basis of the type data being accessed and the issue being investigated. Quantitative and qualitative methods were used with the objective of investigating both the process of implementation and the impact on drug harm.

\section{Background Information}

A background profile of each site was created from general demographic information, local police statistics, the history of how that site got involved in the project and how the trial developed in light of local circumstances.

\section{Official Data Sets}

One of the objectives of the project was to ensure better assessment of outcomes. This involved the use and refinement of existing data collection systems by local drug law enforcement personnel to monitor the impact of their work.

\section{Field Observations}

Field observations were undertaken at both WA trial sites. In the main this involved attending meetings of each DAT. Here group interaction, sharing and interpretation of 
drug-related data, and the feedback on the work undertaken by the project officer were seen as the most important factors.

\section{Police Focus Groups}

A total of nine focus groups were conducted with police officers from the two Western Australian trial sites. These groups sought to identify local police concerns and practice in terms of drug harm reduction.

\section{Interviews with Trial Participants and Key Informants}

Semi-structured interviews were undertaken with DAT and Safer WA Committee members, local law enforcement personnel, centrally-based police drug program coordinators, and key individuals with particular knowledge of community drug matters. Topics covered included respondents' perceptions of local drug-related problems and harms, local drug law enforcement issues, the impact of the trial, the role of the project officer, information sharing and other inter-agency developments, and how the DAT operated in prioritising and responding to drug problems.

\section{Review of Print Media Coverage and Project Documentation}

Newspaper articles on drug issues, minutes of DAT and Safer WA Committee meetings, project officer diaries, project reports were collected and reviewed during the course of the project.

\section{Survey Exploring Police Understanding of Harm Reduction Concepts}

A survey was undertaken with the 302 police officers, who received harm reduction training. This elicited the officers' opinions on the worth of the training provided and explored their perceptions of harm reduction and its utility in the policing of drug use

\section{Challenges in Implementing the Project}

As with any project that breaks new ground in terms of interagency co-operation, there have been difficulties and challenges. Three factors, enthusiasm, size and fit of 
structures, and agency agendas emerged as key influences on how the two WA component trials were able operate and achieve their stated goals.

\section{Enthusiasm}

To be successful, innovative projects require a great deal of involvement and contribution from individuals and organisations. They also require a high level of enthusiasm. This enthusiasm generates motivation and leads to the commitment required for success. From the onset, the project officers were aware that generating and maintaining enthusiasm, particularly within the DAT would be vital to the project's success. The project officers were also under no illusions that generating and maintaining sufficient enthusiasm over the life of the project would be an easy task.

These trials were described and funded by NCBADLE as pilots. As such, the implementation time frame was limited to sixteen months. Prior to project commencement in 1998 all participants were very clear as to this time limit and the fact that no further funding would be made available. It was clear that each site trial would need to be developed quickly. The DATs chose to focus on those areas with the greatest likelihood of short-term success, such as information resources for users and inter agency contact details. Unfortunately, as a consequence of this, there was a limited amount of community and inter agency involvement in project development in the early stages. This made it difficult to subsequently engage local agencies in the project, as they continued to devote their resources to pre-existing activities. Agency involvement was also limited by both the extent and flexibility of their funding. Furthermore, from the agencies' perspectives, what can be made to work over a sixteen month period may not be the best long term strategy or legacy for the community. Some were therefore hesitant in committing themselves to this new initiative.

The limited time frame also placed restraints on the project officers' efforts in creating a positive environment, where police and health agencies could work towards common goals. The establishment of trust and linkages between the police and health agencies occupied a considerable period of the project officer's time. It also required a 
strong commitment of resources from all participating agencies, the benefits of which are only now beginning to be evident.

To add to this, since all parties knew the completion date for the pilot, the project officers experienced increasing difficulty coordinating and progressing activities as the completion date approached. It appears that the agencies that were committed to long term goals and objectives were making choices that reflected this orientation. Unfortunately for the project, this was increasingly a choice to place resources and time elsewhere. This further reduced the effective time frame for the project.

Stability is also important to a project such as this. Establishing trust takes time and often occurs through the direct interaction of individuals. A stable membership of the DAT would enable site trials to advance more quickly than if understandings and relationships had to be developed anew each month. Whilst agency representation on the DATs was relatively stable, both sites experienced considerable turnover in the individuals representing the agencies. Some of the factors affecting this were: workload commitments, changes in roles, movement in and out of the regions, holidays, and conflicting commitments. This had an effect on the motivation and effectiveness of the individuals. In many cases people were either new to the DAT or jaded from the frequent turn over around them. The consequence of this was that it was difficult for individuals to commit themselves to the project. It also reduced the benefits to those members who were able to commit themselves throughout the project.

In the original UK DAT/DRG model, both the DAT and the DRG were seen as arising from a high level of community and agency concern regarding the levels of drug related harm in their communities. It was out of this groundswell of concern that motivated individuals and organisations would come forward to jointly tackle the problems before them. Experience suggests that this "bottom up" approach is in reality quite difficult to achieve with a short-term demonstration project (Pederson et al, 1988; Sabatier, 1986). In WA, the NCBADLE Board selected the pilot sites on the basis of information provided to them regarding levels of harm. Similarly the membership of the DAT and DRG was determined almost exclusively by external agents such as the project officers or agency managers. As a consequence of this 
largely necessary, "top down" approach, the members of the DATs were well placed to represent their organisations. However, the cost was that there was no guarantee that the project was seen as a priority. The members of the DATs tended to be individuals who were on other committees and who had extensive responsibilities outside of the DAT. They also did not necessarily understand the model and there may have been clashes with their agency's existing programs and objectives.

In an attempt to maximise participation, the project officers worked hard to make the project relevant. They regularly contacted the DAT members, providing them with feedback and information on the progress of the various initiatives. The project officers also took a strong role in identifying, developing and instigating initiatives. This has enabled the site trials to move forward and gain some early successes. These early successes were useful in promoting the model and developing interest and stronger motivation. Unfortunately, by working so hard the project officers took on a leadership role in the DAT rather than a facilitator of initiatives. The result of this initially was diminished ownership of initiatives by the agencies. However, over time, as the DATs developed, working groups were able to be formed to tackle specific issues and programmes. Whilst the project officers remained involved in each working group, the groups took on a greater level of responsibility and an increased workload. This freed up some of the project officers' time, but more importantly it increased community ownership because the activity provided a focal point for committee members' involvement and interest.

\section{Size and Fit}

The size of the regions and numbers of agencies and individuals involved had a range of consequences for the two component trials. The Mirrabooka site encompasses the full Police District of Mirrabooka. This region has a population of approximately 230,000 people and encompasses over thirty of Perth's suburbs, not all of which are completely within the police district (Australian Bureau of Statistics, 1997).

Consequently the police district does not represent a single or distinct community, but a number of communities, some of which are only partially represented. As a consequence of this breadth, the DAT was able to include a wide range of health agencies and achieved good coverage of the region. Unfortunately the areas covered 
by the other agencies and area within the police district did not match. Many members had responsibilities outside of the police district and this diminished the DAT's relevance to them and their agencies.

In contrast, the Geraldton DAT focused on the City of Geraldton, which has a population of approximately 20,000 people (Australian Bureau of Statistics, 1997). The city represents only a small part of both the police district and health region. This concentrated the membership and the focus of the DAT to a small and specific group within a distinct geographic community. This was of some advantage, as it limited the scope of the trial to a clearly defined target group. It also enabled the DAT to have some early success in determining its priorities. Unfortunately this group also experienced the problems of a mismatch between the population covered by the DAT and those of the greater police and health districts. Very few members of the DAT or their Safer WA Committee had responsibilities that were solely contained within the City of Geraldton. This resulted in a greater flexibility in interpreting what constituted a legitimate target for the DAT and how initiatives could be of use to the wider police and health districts. Consequently some of the actions of the DAT reached beyond the area targeted in their original brief. This was not necessarily a negative outcome in the broader sense, but had consequences for the trial. These out of area initiatives consumed resources, but for the purpose of the evaluation, could not be counted as benefits.

In order to increase the level of agency support for the project, both project officers tried to incorporate and promote those aspects of project that were transportable beyond the DAT regions. This enabled agencies to more clearly see the potential of the initiatives and the possible benefits for their target populations.

The number of DAT members was also an important consideration for each site trial. In Mirrabooka the DAT comprised of up to 19 members. This had some advantages, as a comprehensive representation of service agencies could be maintained despite decreasing attendance towards the end of the trial. Again however, this came at a cost. Earlier, when attendance was higher, the large group size complicated the chairing of meetings. To overcome these problems, the project officer adopted a strict protocol and agenda for each DAT meeting. He also made attempts to provide new or 
returning members with a brief summary of the activities of the DAT, either prior to or after each DAT meeting. In later stages the size of the committee, coupled with poorer attendance meant that members were less than completely briefed on the past actions and motions of the DAT. In a number of other ways the size of the Mirrabooka DAT reduced its effectiveness. Members were less likely to feel obligated to attend, as their absences was less evident and their contribution less vital. Such a large body with diverse professional backgrounds, different agendas, opinions, and experiences also made the job of prioritising the objectives for the DAT more difficult.

In Geraldton the DAT membership was much smaller, resulting in a tighter and more cohesive group. This was a considerable advantage for decision making by the DAT, but as membership numbers decreased later in the trial, this left large gaps in representation and reduced the DAT's ability to function. The nature of the smaller group also meant that is was more difficult to express dissenting views. There was a marked lack of critical discussion of initiatives within the DAT meetings, which may have limited the exploration of possible initiatives in Geraldton.

\section{Different Agendas}

As outlined earlier, not everyone involved in the DATs or Safer WA Committees held the same underlying beliefs about what constitutes good or effective drug law enforcement. It was not well understood that the concept of harm reduction encompasses a wide range of activities and beliefs: for example, harm reduction can legitimately focus on the community as well as the individual. As a consequence of this, a shared understanding of what constitutes harm reduction was not achieved by either DAT. Subsequently, whilst each agency of itself had harm reduction or harm reduction as an objective, their own particular understanding of these terms contributed to the development of separate agency programs, which were not always generally acceptable.

This goes to the core of what the DAT members believed their respective agencies were established to achieve. The project officers were unable to do a great deal more than acknowledge the differing views and attempt to accommodate them in a mutually 
satisfactory manner. Interestingly, the police were generally more willing to entertain new approaches. A number of structural factors were likely to have contributed to this, such as the hierarchical nature of police management, which could serve to direct change. Police were initially more focused on the community harm associated with drug use. However, their sensitivity to the harm experienced by individual drug users increased during the course of the project. Police deal very closely with individuals involved in drug use and this may have made it easier for them to respond to issues of individual harm. In contrast, health agencies, which traditionally focus on individual harm, seemed to find it more difficult to incorporate a community harm perspective. In addition, in the WA Police Service, there appears to have developed what many police describe as an "environment of change". This NCDABLE project is not the only new initiative being tried or implemented by the police in WA. Police officers have grown accustomed to change, accept that it is necessary, and expect positive consequences. This more open and outward looking police culture has in many ways made it easier to introduce innovative projects.

There was some confusion between the agencies as to each other's key areas of responsibility. In some instances there were also poorly defined lines for communicating between and within agencies. This caused considerable frustration, particularly on the part of the police, who were often left with the problem of trying to determine who to contact in relation to a particular problem.

For the project officers, these difficulties were particularly complex and delicate. One strategy used by the project officers was to attempt to identify and make transparent the core duties of each of the agencies represented on the DAT. It was hoped that this would clarify roles and reduce the confusion and misinformation evident. This met with some success, but unfortunately not all agencies within the regions were represented on the DAT. Their roles therefore, could not be clarified in this direct manner. The success was also limited by the fact that not all agencies, for various reasons, were able to provide this information.

\section{The Impact of the Project}


Despite these difficulties with how the model was put into place within the two WA regions, differing understandings of what the DAT should set out to achieve, how the various agencies could contribute to this, and practical problems such as the size of the DAT committees, the two trials have achieved some successes. Both in Geraldton and Mirrabooka, police specific harm reduction training was added to the training programs for all police in those regions. This resulted in over 300 police of all ranks attending an interactive harm reduction workshop. The workshop covered topics such as: what are drugs, the pharmacological effects of various drugs, harms to the community and to the user, harm reducing options, and the use of discretion in responding breaches of the law. Following each workshop there was a thirty-minute briefing on the NCBADLE project and a presentation by an ex-drug user. These exusers spoke on why they had used drugs, why they stopped, the effect of their interactions with the police.

As part of the evaluation, the WA project evaluator asked the officers to complete a number of forms, including a questionnaire on the training. This indicated that the workshop was well received by police officers, particularly the presentation by the exuser. Whilst a number of the police officers felt that the training merely repackaged existing good police practices, they were able to identify the harm reduction qualities of past actions. In addition they identified other initiatives that they could realistically incorporate into their policing. The presentation by the ex user was found to be particularly interesting and useful to the police. Many stated that they had not previously been aware of the far-reaching effects of their actions on users, nor the long term turmoil and difficulties underlying users' day to day behaviours.

As a complement to the harm reduction training, both DATs devised a "Drug Reference Card" (see Figure 1). This credit card sized, folded card was developed for use by the police. It provides local referral and support information for users and those at risk of illicit drug use. The card contains emergency information and contact details for counselling, detoxification, and support services in the local area. In a six month period over 2000 of these cards were distributed by the police during the course of their normal operational activities. Police have reported feeling positive about their experiences in distributing the cards. The cards provide a window of opportunity for the user to seek counselling and support and where no charge has been 
laid, provide the police with an opportunity to do something positive for at risk individuals. There is some evidence of the benefit of this emerging in both Mirrabooka and Geraldton. In a number of instances, individuals attending counselling and support services indicated that they had received one of the cards from the police.

\section{Want to know more about ........ \\ Remember - if someone drops Call an Ambulance - they won't call the cops unless they feel threatened \\ IN CASE OF EMERGENCY DIAL 000 \\ Always dispose of needles \& syringes safely. This card is a NCBADLE Project Initiative}

\begin{tabular}{|c|c|}
\hline \multicolumn{2}{|c|}{ Perth Drug and Alcohol Services } \\
\hline \multicolumn{2}{|c|}{ Counselling } \\
\hline & 94425000 \\
\hline $\begin{array}{l}\text { N Metro Community Drug Service Team } \\
\text { NE Metro Community Drug Service Team }\end{array}$ & $\begin{array}{l}93003746 \\
92747055\end{array}$ \\
\hline & $\begin{array}{l}92747055 \\
93287355\end{array}$ \\
\hline $\begin{array}{l}\text { Palmerston } \\
\text { Holyoake }\end{array}$ & $\begin{array}{l}93287355 \\
93289733\end{array}$ \\
\hline Cyrenian House & 93289200 \\
\hline Parent Drug Information Service & 94425050 \\
\hline $\begin{array}{l}\text { Perth Womens Centre } \\
\text { Pun }\end{array}$ & 92279032 \\
\hline nce Abuse Service & 92211411 \\
\hline Youth Services & \\
\hline $\begin{array}{l}\text { Yirra } \\
\text { Samaritans Youthline }\end{array}$ & $\begin{array}{l}93286755 \\
93882500\end{array}$ \\
\hline (MoJ) Killara - 12 to 18 yo & 94709255 \\
\hline Youth Legal Service & 93289077 \\
\hline Kids Help line & 1800551800 \\
\hline Balga Detached Youth Service & 94404667 \\
\hline \multirow{2}{*}{\multicolumn{2}{|c|}{ Information \& Referral }} \\
\hline & \\
\hline e (24hrs emergency Youth accom) & 93251111 \\
\hline Mission (Youth accom/food) & 94211199 \\
\hline & \\
\hline WA Substance Users Association & 92277866 \\
\hline \multicolumn{2}{|c|}{$\begin{array}{l}\text { The wa Police Service does not condone illiciti truy use, } \\
\text { this intormation is provided in the interests of community health }\end{array}$} \\
\hline \multicolumn{2}{|c|}{ Needle \& Syringe Exchanges } \\
\hline WA Substance Users Association & 92277866 \\
\hline WAAC Mobile Needle Exchange Van & 0417093537 \\
\hline Derbarl Yerrigan Mobile Needle Exchange & 014081925 \\
\hline
\end{tabular}

Figure 1 The Drug Reference Card Used by Police

These two activities had additional benefits. The fact that the police are tackling harm reduction in a transparent and practical manner is seen by the health agencies as a positive and proactive move. There has been a noticeable increase in the level and quality of cooperation between the police and health agencies and whilst there was some initial resistance by both parties, this has now largely dissipated. Both the police and the health agencies have moved ground and have a better appreciation of each other's objectives and modes of operation.

\section{Conclusion}


The tasks set by the NCBADLE Board of Control for this project were both difficult and wide ranging. Bringing about fundamental changes in a large, complex organisation such as the police service takes a long time and considerable effort. Even when there is support for a new approach a considerable amount of procedural inertia means that operational change can lag by several months. Added to this was the need to establish, or further develop linkages between the police and other agencies and better assess outcomes. There have been problems. However, the value of the NCBADLE initiative should not be determined just in terms of the problems it identified, but in its legacy.

Over 300 police have received specific drug harm reduction training. This training has now become part of the recruit training and is being incorporated into the ongoing training for the remaining police regions. During the course of the project there seems to have been a gradual change in the actions of police, with greater willingness to make decisions that reduce harms for individual users and a broader re-appraisal of the value of harm reduction in the police context. There were also benefits to police in terms of greater collaboration with other agencies dealing with drug problems and a number of productive joint operations were conducted because of decisions made by the DATs. As a consequence the police have seen that they can work productively with other agencies in a way that respects differing objectives and methods. The collaborating agencies also benefited from the partnership, because rather than each agency separately providing its mandated service they contributed to an integrated problem focused response. A further benefit was that the DAT meetings provided an opportunity for all local agencies with involvement in the drug field to make contact with each other. This meant that other collaborative arrangements were made in addition to those involving police.

In terms of the five objectives specified for the project by the NCBADLE Board of Control, there was broad, demonstrable achievement. The intersectoral structure of the DATs showed how a framework could be developed to better integrate drug policing and give a greater focus to harm reduction. In their operation the DATs demonstrated intersectoral partnership and incorporation of harm reduction. Police drug training also changed as a consequence of the project. However, because of the short time frame and other restrictions on this project, less was able to be achieved in 
terms of changing the culture of police drug law enforcement and in developing and utilising common data collection systems. In the Sutton and James (1996) model, these were important recommendations and more time, effort, and resources will be needed if such changes are to be achieved. The lessons learnt from this pilot will hopefully enable ensuing initiatives to be more successful in this regard. Similar future initiatives will need to quickly come to terms with the realities of established policing priorities and the sensitivities of working with a broad range of community agencies. Change can be achieved, but it is likely to be gradual, as agency norms and practice traditions change. There also needs to be recognition that short term, 'top down' projects are unlikely to institutionalise change without long term follow up and support.

\section{Acknowledgments}

This study was funded by the National Community Based Approach to Drug Law Enforcement (NCBADLE) Board of Control. An earlier version of this paper was presented at the Australian Professional Society on Alcohol and Other Drugs (APSAD) national conference held 20-22 November 2000.

\section{References}

Australian Bureau of Statistics. Population by Age and Sex Western Australia, ABS Catalogue no. 3235.5, 1997.

Duke, K, MacGregor, S. Tackling Drugs Locally: The Implementation of Drug Action Teams in England, London: HMSO, 1997.

Gruenewald PJ, Treno AJ, Taff G, Klitzner M. Measuring Community Indicators, Thousand Oaks, CA: Sage Publication, 1996.

Hall, W. The Australian Debate About the Legalization of Heroin and Other Illicit Drugs, 1988-1991. Journal of Drug Issues, 1992;22:563-578. 
Holder HD. What is a community and what are implications for prevention trials for reducing alcohol problems?. In Holder HD, Howard JM, editors. Community Prevention Trials for Alcohol Problems,15-33. Westport, CT: Praeger Publishers, 1992.

Lord President of the Council et al. Tackling Drugs Together: A Consultation Document on a Strategy for England 1995-98, London: Her Majesty's Stationary Office, 1995.

National Community Based Approach to Drug Law Enforcement. Terms of Reference, undated.

National Drug Strategy Committee. National Drug Strategic Plan 1993-97, Canberra: Australian Government Publishing Service, 1993.

Parliamentary Joint Committee on the National Crime Authority. Drugs, Crime and Society, Canberra: Australian Government Printing Service, 1989.

Pederson AP, Edwards RK, Marshall VW, Allison KR, Kelner M. Coordinating Healthy Public Policy: An Analytic Literature Review and Bibliography, Toronto: University of Toronto, 1988.

Sabatier, PA. Top-down and bottom-up approaches to implementation research: A critical analysis and suggested synthesis. Journal of Public Policy 1986;6:21-48.

Sutton A, James S, Evaluation of Australian Drug Anti-trafficking Law Enforcement, Payneham, SA: National Police Research Unit, 1996. 